\title{
Las mujeres víctimas de El Salado: Una reflexión ética del conflicto armado*
}

\author{
Maria Camila Hernández Ceballos** \\ (camilapocha@hotmail.com)
}

Artículo corto recibido el 02/10/2015 y aprobado el 12/11/2015

Cómo citar este artículo:

HERNÁNDEZ CEBALLOS, María Camila. (2015). "Las mujeres víctimas de El Salado: Una reflexión ética del conflicto armado". En: Trans-pasando Fronteras, Núm. 8, pp. 53-65. Cali, Colombia: Estudios Interdisciplinarios, Jurídicos, Sociales y Humanistas (CIES), Facultad de Derecho y Ciencias sociales, Universidad Icesi

DOI: $10.18046 /$ retf.i8.2119

\section{Resumen}

Este ensayo busca analizar, desde una perspectiva ética, los daños causados sobre las mujeres víctimas de violencia sexual en el contexto del conflicto armado, con énfasis especial en la situación vivida por las mujeres de El Salado y la violencia perpetrada por los paramilitares, una de las más sanguinarias y sádicas ejercidas en el marco del conflicto armado colombiano. También pretende analizar, después de 15 años de esta masacre, cuáles han sido las dinámicas de resistencia que han realizado las mujeres víctimas, además de sus procesos de reconstrucción de memoria, a través de la teoría de la ética de la memoria. Además, de realizar una reflexión sobre los daños que ha causado el conflicto armado a la participación política de las mujeres y el fortalecimiento de la democracia. Finalmente, a través de las teorías de la ética

* Este ensayo se presenta como un producto para el "Primer concurso de Ensayo Ético del Centro de Ética y Democracia de la Universidad Icesi”. Octubre 2015.

** Estudiante de Ciencia Política de la Universidad Icesi. 
de la responsabilidad y del compromiso, entender la responsabilidad del Estado frente a los hechos y la responsabilidad que, como mujer y ciudadana, debo asumir frente al conflicto y las injusticias estructurales contra las mujeres que en él se replican.

\section{Palabras clave}

Mujeres víctimas,Violencia sexual, Masacre de El Salado, Ética de la responsabilidad.

\section{Introducción}

La masacre de El Salado, al igual que otras de las masacres que han perpetrado paramilitares y guerrilleros en diferentes zonas del país, son un claro ejemplo de la violencia sociopolítica asociada a la implementación de diferentes tipos de violencias como herramientas de guerra, en el contexto de un conflicto armado interno que ha dejado miles de víctimas en los últimos cincuenta años. La gravedad del conflicto armado ha sido analizada por múltiples actores, en escenarios académicos y no académicos, como un fenómeno socio-político que pareciera asilado de la cotidianidad de las ciudades. No obstante, en los últimos años, diversas organizaciones han tratado de abordar el tema desde una perspectiva más humana, más cercana a cada individuo, reconstruyendo la memoria de las víctimas y analizando el conflicto armado como una problemática que nos involucra a todos como ciudadanos. De alguna manera, se han encargado de explicarnos la gravedad del conflicto, de mostrarnos con detalle lo que han tenido que soportar las víctimas, hasta el punto de hacernos reflexionar sobre nuestro papel dentro de toda esta problemática.

Ahora bien,el siguiente ensayo se construye a través del análisis de estas perspectivas más cercanas, entre las que se pueden destacar no solo los relatos periodísticos sobre la masacre y sus víctimas, sino también estudios más minuciosos sobre lo acontecido (los daños, las nuevas dinámicas socio-políticas, el territorio, etc.). En él se analizarán, a través de los conceptos de ética y moral, la situación que han vivido las víctimas en el contexto de la violencia en El Salado, con énfasis particular en las mujeres víctimas de violencia sexual por los actores armados, de quienes el país apenas comienza a ser consciente, con el objetivo de reflexionar sobre los daños que el conflicto les ha causado, las formas de resistencia que han desarrollado después de 15 años de la masacre y la responsabilidad que tenemos como ciudadanos frente a esta situación. 
De acuerdo a lo anterior, este ensayo se divide en cuatro secciones. La primera reconstruye de manera breve la historia de la masacre de El Salado, a través de los testimonios de víctimas y victimarios, con el objetivo de contextualizar la problemática. Es importante destacar que la descripción de los hechos es realizada a través de una reconstrucción de los testimonios recolectados en la prensa y otras fuentes secundarias. La segunda sección, analiza los daños físicos, morales y socio-culturales que la violencia sexual y el conflicto armado han causado en las mujeres de este municipio. Posteriormente, la tercera sección muestra ejemplos de resistencia pacífica, ejecutados por los grupos de mujeres víctimas, 15 años después de lo sucedido. Finalmente, a manera de conclusión, la cuarta sección propone una reflexión desde la teoría de la ética de la responsabilidad y el compromiso, en donde se busca analizar cuál ha sido la responsabilidad del Estado en esta masacre y la responsabilidad política y social que tenemos los ciudadanos como agentes de cambio, que buscan fortalecer la democracia y con ella la dignidad, la equidad y la libertad en toda la sociedad.

\section{La masacre de EI Salado: una historia dificil de contar}

"Los saladeños presentían que algo terrible iba a ocurrir. En los últimos meses había señales de muerte por todos lados" (Ruiz, 2008). Lastimosamente este presentimiento fue cierto. Entre el 16 y el 21 de febrero del año 2000, 450 paramilitares incursionaron en cuatro municipios del departamento de Bolívar y Sucre, entre ellos El Salado, allí torturaron, masacraron, asesinaron y cometieron delitos sexuales, dejando más de 100 personas muertas. Una de las masacres más sanguinarias perpetradas por las AUC.

"Cuando llegamos a El Salado mandamos a recoger la gente y la reunimos en la plaza, junto a la iglesia. Los desertores señalaban a los guerrilleros y los íbamos ejecutando" (Ruiz, 2008). Así relató "Juancho Dique”, uno de los perpetradores. Él, junto con su comandante Luis Francisco Robles Mendoza, alias "Amaury", Jhon Jairo Esquivel Cuadrado, "el Tigre” y Uber Enrique Bánquez Martínez, todos bajo las órdenes de alias "Jorge 40" y "Salvatore Mancuso", fueron los autores de múltiples asesinatos, torturas y degollamientos. Pero también de crímenes como violaciones y tortura contra las mujeres y niñas de El Salado, porque creían que eran amigas, novias o esposas de los guerrilleros. 
Es importante resaltar que el accionar paramilitar y la justificación de los delitos cometidos, tanto al momento de perpetrarlos como en el momento de ser juzgados por ellos, se da a través de una forma de argumentación moral propuesta por Annemarie Pieper (Pieper, 1991) en donde se apela a una autoridad, a la cual se respeta y obedece de manera ciega, para creer en la justificación moral de una acción. Para ponerlo en términos específicos, los hechos perpetrados por los paramilitares en El Salado son justificados por medio de las ordenes que dieron alias " Jorge 40" y " Salvatore Mancuso", que consistían en asesinar a los guerrilleros y a todo aquel que tuviera, o se creyera que tuviera, relaciones con ellos.

Por tal razón, los paramilitares comenzaron la masacre persiguiendo y acusando a aquellos que creían eran guerrilleros, pero una vez se les acabaron esos "supuestos blancos" que tenían identificados comenzaron a matar a todo el que creyeran cómplice o ayudante de los guerrilleros, a través de sorteos o rifas, sin ningún tipo de pruebas que respaldaran estas relaciones ni tampoco ningún tipo de reflexión sobre las dimensiones de los daños que le estaban causando a personas inocentes.

El 18 de febrero, a las 8 de la mañana se escucharon varios disparos en el pueblo de El Salado. Las familias ya sabían que se trataba de los Paramilitares y con esperanza de salvar sus vidas huyeron a las afueras del pueblo para esconderse en diferentes casas. No obstante, hasta estos lugares llegaron los paramilitares, quienes con un helicóptero y cientos de hombres armados hicieron que varios hombres y mujeres fueran, por la fuerza, hasta la cancha del pueblo. Ahí separaron a los hombres de las mujeres. A ellas las llevaron, cerca de las 11 de la mañana, a la iglesia, donde les hicieron interrogatorios, ya que los paramilitares buscaban asesinar a las mujeres que tuvieran relaciones con los guerrilleros (Ruiz, 2008), y a ellos los retuvieron en la cancha, el lugar en donde ocurrieron la mayoría de crímenes.

\section{Las mujeres de EI Salado: víctimas de múltiples daños}

En este punto, un concepto que requiere atención es la idea de víctima. En este sentido una víctima es aquella persona a la que se le han vulnerado sus derechos fundamentales y sufre los daños causados por el conflicto, que desde una perspectiva moral son irreparables. En el caso de las mujeres, éstas son víctimas no solo de la violencia infringida sobre 
sus cuerpos, a través del abuso sexual y la tortura, sino que también sufren daños psicológicos que impiden el desarrollo de su autoestima y su libertad en la sociedad. Respecto a este último punto, es importante resaltar que las mujeres víctimas están inmersas en dinámicas patriarcales, que replican discursos machistas en los que se degrada el cuerpo de la mujer y su autonomía frente a las decisiones relacionadas con su sexualidad y su futuro. En este sentido, en las dinámicas del conflicto el papel de la mujer se restringe a la esfera privada y al rol reproductivo.

Estas ideas están directamente relacionadas con injusticas estructurales que viven las mujeres colombianas, día a día, en esta sociedad patriarcal. Dichas injusticias, entendidas como problemas socio-políticos que afectan a los individuos y que son causados por diferentes actores (Young, 2011), están relacionadas con la discriminación de las mujeres por cuestiones de género, su falta de participación en los espacios de poder y de toma de decisiones y la cosificación de sus cuerpos a través de los medios de comunicación, lo que hace que se repliquen dichos discursos en toda la sociedad. Todos estos factores ponen a las mujeres víctimas del conflicto en situación de indefensión y vulnerabilidad, ante una sociedad que no alcanza a dimensionar los daños que en ellas ha plasmado el conflicto armado.

Para los actores armados, legales o ilegales, los cuerpos de las mujeres se habían vuelto objetos de guerra, que servían para vengarse y herir la masculinidad y el ego de los enemigos. De esta manera muchas mujeres fueron asesinadas brutalmente y otras violadas por ellos en lo transcurrido de los enfrentamientos.

Estos hechos tienen como responsables no solo a los paramilitares, aunque los estudios realizados por organizaciones como la Corporación Humanas señalan que estos delitos han sido en su mayoría perpetrados por ellos (Corporación Humanas, 2009), sino a todos los actores armados que han utilizado a las mujeres en diferentes contextos. En la última década, según la representante Ángela María Robledo, cerca de 400.000 mujeres han sido abusadas sexualmente, en el marco del conflicto armado (Semana, 2012), siendo estas las cifras oficiales. Por otro lado, el estudio "Primera encuesta de prevalencia de la violencia sexual en contra de las mujeres en el contexto del conflicto armado" (apoyada por ONG internacionales como OXFAM), realizado en el 2010, en 407 municipios colombianos con presencia de actores del conflicto, revela que, entre el 2001 y el 2009, 489.687 mujeres declararon 
haber sido víctimas de violencia sexual. 74.698 de ellas responsabilizaron a actores ilegales (guerrillas y paramilitares), mientras 21.036 a la fuerza pública.

El Salado, no fue la excepción a esta triste realidad, ya que durante la masacre los paramilitares a través de la tortura y la denigración, asesinaron a ocho mujeres y violaron a dos más (Grupo de Memoria Histórica, 2009), que sobrevivieron para narrar sus historias, como fue el caso de Jennifer ${ }^{1}$, una joven de 15 años de edad que vivía con su familia y fue sacada de su casa el 18 de febrero del 2000.

“¿Tú sabes lo que te va a pasar muchacha?” (Roldán, 2015), le dijo uno de los paramilitares a la joven de apenas 15 años que llevaron hasta una casa de mando, porque desobedeció las órdenes que le dieron y aseguró que El Salado era un territorio guerrillero. Después, "el castigo" que infringieron sobre ella, fue monstruoso, cruel y desgarrador.

\begin{abstract}
“El jefe paramilitar la arrastró hasta una habitación. Se bajó los pantalones y fue el primero en abusar de ella. Después de golpearla, le dijo a los demás que hicieran con ella lo que quisieran (...) Entre todos le cortaron el pelo, le pintaron el rostro como a un payaso, le tatuaron una cruz en su pierna derecha y le lanzaron insultos y burlas que ya no recuerda. Luego de ser violada por segunda vez sintió que se estaba desangrando y quedó inconsciente" (Roldán, 2015).
\end{abstract}

Ahora bien, las personas que vivimos en las principales ciudades y que no hemos sido marcadas por el conflicto de manera directa, no alcanzamos a imaginar que, delitos de esta gravedad estuvieran cometiéndose en diferentes zonas del país. Solo en las últimas décadas hemos conocido, por medio de los medios de comunicación y las diferentes investigaciones, los desgarradores relatos de las mujeres víctimas y de manera indirecta hemos tratado de entender los daños que el conflicto les ha causado.

Para las mujeres colombianas, el conflicto armado ha sido un arma de doble filo, ya que sobre ellas se ha ejercido no solo la violencia sociopolítica del conflicto, sino que también han sido sometidas a abuso y violencia sexual con el fin de ser dominadas, castigadas, como fue el caso de la joven descrito anteriormente, o extorsionadas.

1 Este es el nombre ficticio que usan en la crónica "Cuando los paramilitares me arrancaron la inocencia” del periódico El Tiempo (2015), debido a una petición de las fuentes que narraron los hechos. 
Retomando el angustiante caso que tuvo que vivir Jennifer, se hacen evidentes los múltiples daños que esto le causó a su vida y a la vida de sus familias. En un proceso de reconstrucción de los hechos, se puede observar que esta joven sufrió daños físicos, pues su cuerpo fue maltratado, su cabello cortado y su piel tatuada, y fuertes daños psicológicos, entendidos como "las huellas emocionales que deja la guerra" (Centro Nacional de Memoria Histórica, 2012, pág. 261), que cambiaron su personalidad y le arrebataron la confianza en sí misma, causando fuertes impactos emocionales.

"Durante los 30 días que siguieron al 18 de febrero del 2000, Jennifer no dijo una palabra (...) estaba muda (...) La agobiaba la gente, el ruido, la luz (...) una y otra vez se bañaba a totumazos, como si el agua limpiara la turbiedad del alma, como si el agua aliviara las penas, como si el agua se llevara las desgracias" (Roldán, 2015).

También sufrió daños morales profundos, que se definen como "toda manifestación dolorosa del espíritu, consiste en profundas preocupaciones o estados de aguda irritación que afectan el honor, la reputación y el equilibrio anímico de las personas, que incide en la aptitud del pensar, de querer o sentir" (Centro Nacional de Memoria Histórica, 2012, pág. 268). En este sentido Jennifer no solo se sentía aturdida por los hechos, sino que su manera de ver la vida se transformó debido a que había perdido la libertad sobre su cuerpo, su dignidad y también sus ganas de vivir. Por este proceso traumático, que implica valentía para poder reconstruir en el futuro sus proyectos de vida y además para luchar contra la impunidad de los delitos cometidos, han tenido que pasar miles de mujeres colombianas que han sido abusadas y violentadas sexualmente.

Ahora bien, de manera más general, las mujeres víctimas de la masacre también sufrieron daños socioculturales, ya que su manera de vivir en la comunidad nunca más volvió a ser la misma. Estas mujeres, debido a sus traumas y temores, prefirieron abandonar sus tierras y con ellas sus prácticas cotidianas colectivas y los espacios y formas de encuentro, como las fiestas y las celebraciones del pueblo. En este sentido, el daño infringido sobre ellas no solo transformó aspectos personales de sus vidas, sino que también modificó drásticamente la lógica de las relaciones de poder en la comunidad. 


\section{La resistencia femenina y su construcción de memoria}

El proceso de construcción de memoria de las víctimas de El Salado ha estado enfocado en diferentes acciones por parte de las víctimas. La primera de ellas, que fue el común denominador de las mujeres víctimas de violencia sexual, consistió en el silencio. Un silencio que se desplegaba como una manera de procesar el duelo o como una estrategia de supervivencia utilizada por miedo a ser re victimizadas, señaladas o juzgadas (Grupo de Memoria Histórica, 2009). No obstante, una vez pasados los años, dicho proceso comenzó a transformarse, las mujeres víctimas comenzaron a escucharse y a buscar quien las escuchara, las defendiera y las apoyara. En este contexto se dio una de las manifestaciones más importantes de resistencia llevada a cabo por grupos de mujeres víctimas, que fue romper ese silencio.

Para superar todo lo sucedido y mitigar los daños causados, las mujeres víctimas de El Salado y sus familias, acompañadas de organizaciones de la sociedad civil que les han brindado apoyo jurídico y psicológico, han desarrollado de manera pacífica proyectos para reconstruir la memoria de los hechos, proceso que les ayuda a fortalecer su autoestima y sus habilidades como lideresas de su comunidad. De esta manera, a través de marchas, manifestaciones, proyectos con diferentes organizaciones, como la creación de murales o monumentos, le han mostrado al país qué fue lo que ocurrió en El Salado y cómo ellas siguen luchado hasta el día de hoy por sus derechos, por justicia y por el fin del conflicto.

Otra manifestación de resistencia realizada por las víctimas de El Salado ha sido el retorno a sus tierras, para recuperar su historia, su identidad y sus costumbres. Luego de la masacre del 2000, en donde fueron desterrados cerca de 4.000 Saladeños (Grupo de Memoria Histórica, 2009, pág. 14), han retornado cerca de personas 750 al corregimiento (Ruiz, 2008) . Dichas personas intentan con fortaleza reconstruir su vida, regresando a sus tierras y buscando recuperar todo lo que perdieron hace tantos años. No obstante, este retorno ha sido difícil, ya que el regreso al lugar de la masacre revive los recuerdos traumáticos de la experiencia vivida hace más de 15 años.

Dentro de esos éxodos, grupos de mujeres han querido retornar a sus tierras en lo que se ha denominado un retorno simbólico. Estos retornos consisten en marchas pacíficas que se hacen hacia lo que ha quedado del territorio en conflicto, en donde los lugares y el entorno representan un momento de la vida de los saladeños que preferirían no recordar, 
pero que les permite reconstruir la memoria de las víctimas y mostrarle al país, a través de los medios de comunicación, que las mujeres y hombres que vivieron este trágico episodio no quieren que vuelva a suceder.

El retorno de las mujeres víctimas de la masacre a El Salado es también una forma de reconstrucción de sus memorias, ya que las mujeres recuerdan con nostalgia sus tierras, las actividades que realizaban en ellas y los hechos traumáticos a los que sobrevivieron, con el objetivo de reflexionar, reparar y luchar contra la impunidad. Desde una perspectiva ética, la reconstrucción de la memoria de las víctimas es esencial, ya que configura nuestra memoria histórica colectiva y nos permite reflexionar sobre el futuro de nuestra sociedad. Hay que enfatizar en la importancia de la reconstrucción de la memoria desde las mujeres particularmente, ya que este es un proceso específico y particular, debido al contexto socio-político en el que vivimos las mujeres en el país.

De acuerdo a lo anterior, es menester destacar que la reconstrucción de la memoria de las mujeres víctimas de violencia en el contexto del conflicto, es un importante logro en una sociedad en donde las mujeres han sido excluidas históricamente de la esfera política y pública. En este sentido, que las mujeres logren unir sus voces y demandarle a la sociedad de manera pacífica y organizada el respeto de sus derechos y que le pidan al Estado garantías de justicia y no repetición, son grandes pasos en la construcción de una democracia realmente incluyente.

Un ejemplo de lo anterior se llevó a cabo el 24 de agosto de este año, a través de una de las seis marchas de la campaña "No es hora de callar" (Montaño, 2015), liderada por víctimas de violencia sexual, que busca, a través de actos de resistencia pacífica, luchar por los derechos de las mujeres y concientizar a la sociedad para que los hechos vividos en El Salado y en otras regiones del país, que han afectado a tantas mujeres y sus familias, no queden impunes.

Esta forma de activismo contra la violencia es sin duda un modelo de conexión social desarrollado por mujeres (Young, 2011), que permite evidenciar cómo la sociedad, representada por ellas y otros grupos y organizaciones, participan en conjunto, asumiendo la responsabilidad de manera colectiva y luchando para que no se vuelvan a repetir esas injusticias. Los reclamos por la verdad y resarcimiento de la dignidad de las víctimas es una demanda que debe unirnos, como mujeres y como ciudadanas. 


\section{La masacre de EI Salado y un conjunto de responsables}

Esta masacre, que como se ha descrito dejó daños imborrables en las victimas y marcó la memoria colectiva de los Colombianos, es un hecho que nos invita a reflexionar sobre el conjunto de acciones y actores que hicieron parte de este engranaje del terror. Esta reflexión es posible debido a la capacidad que tenemos todos de deliberar, decidir y elegir sobre la justicia de las acciones propias y de los demás (Agrest, 2011).

En este sentido, como se desarrolló anteriormente, los crímenes cometidos en el Salado tienen actores intelectuales que están siendo juzgados actualmente. No obstante, esta masacre no es un hecho aislado del Estado y de la ciudadanía misma. Por tal motivo, es importante cuestionarse sobre la responsabilidad que tuvo el Estado Colombiano en estos crímenes y la responsabilidad que debemos asumir todos los colombianos para que lo que ocurrió en El Salado no vuelva a suceder.

En el contexto del conflicto armado, la responsabilidad que tiene el Estado radica en su incapacidad para garantizar la seguridad de los habitantes de El Salado y en muchas ocasiones por colaborar con las acciones llevadas a cabo por los paramilitares en contra la población civil, ya que muchas investigaciones apunta a que los militares estuvieron comprometidos con algunos hechos. Frente a esto, en los años posteriores a la masacre, el Estado ha tenido el deber de garantizar la reparación integral de las víctimas de estos crímenes. En cuanto a las mujeres víctimas de violencia sexual, se trata de una reparación que requiere no solo de indemnizaciones y acompañamiento jurídico, sino de un acompañamiento psicosocial y de empoderamiento de las mujeres, para que puedan afrontar estos hechos traumáticos y reconstruir sus vidas a través del fortalecimiento de su autoestima y su autonomía. Para esto, el Estado ha intentado construir redes institucionales en donde se vinculan la Unidad de Reparación de víctimas, las Secretarias municipales de mujeres, las Comisarias de Familia, entre otras, para acompañar y realizar seguimiento de los casos de mujeres víctimas de violencia sexual.

No obstante, esas iniciativas estatales se quedan cortas a la hora de realizar una reparación integral. "El Estado no ha llevado a término su obligación de identificar, procesar y castigar a todos los responsables materiales e intelectuales de la masacre, las torturas, los secuestros, los tratos denigrantes, la violencia sexual, el desplazamiento forzado, las lesiones personales y demás atrocidades contra la población inerme" (Grupo de Memoria 
Histórica, 2009: 19). Por tal motivo, organizaciones de la sociedad civil, en su mayoría construidas a través de la acción colectiva de muchas mujeres, han acompañado a las víctimas y desarrollado campañas para concientizar a los colombianos y colombianas de la importancia de reconocer los derechos de las víctimas, luchar contra la impunidad y velar por el cumplimiento de las leyes y normas, tanto nacionales como internacionales, que buscan proteger a las mujeres frente a cualquier tipo de violencia. En este sentido, es importante resaltar la labor que realizan estas organizaciones, lo que demuestra que en la sociedad aún prevalece la solidaridad y la motivación de reconstruir un país mejor.

Frente a lo anterior, surge la pregunta sobre la responsabilidad que tenemos todos los ciudadanos de garantizar la dignidad y libertad de los demás. De acuerdo a lo anterior, aunque resulta alentador ver que muchas personas han realizado diferentes acciones para transformar las dinámicas que replican el conflicto y luchar para que las injusticas estructurales que tienen que vivir las mujeres dentro de la sociedad se acaben, es importante reflexionar sobre qué estamos haciendo usted y yo para contribuir. En este sentido, debemos evitar como ciudadanos que se continúe naturalizando el conflicto, en cualquiera de sus manifestaciones, comenzado por transformar las prácticas machistas que promueven la violencia de género y aquellas que replican un discurso en donde los hombres y las mujeres no tenemos los mismos derechos. También debemos despertemos de este estado de indiferencia, apatía e indolencia frente al dolor de las víctimas, frente al dolor de los niños, las mujeres y los hombres colombianos que han tenido que sobrevivir a una guerra que no les pertenece. Debemos dejar de liberarnos de la culpa (Capella, 1993) y reaccionar ante esta anomia moral que nos hace cómplices de los crímenes cometidos, ya que el silencio, la conformidad o a falta de acción pueden confundirse con una forma de complicidad que aumenta las injusticias y las desigualdades sociales. Debemos reaccionar y actuar contra la impunidad que han tenido el caso de Jennifer y los casos de las miles de mujeres víctimas de violencia sexual dentro y fuera del contexto del conflicto armado.

Esta lucha debe darse a través de la protesta pacífica y la reconstrucción de las memorias colectivas, como formas de solidaridad y herramientas para hacer conscientes a las nuevas generaciones de la necesidad de reescribir una historia alejada de cualquier tipo de violencia contra la mujer. Con esto también se espera que los ciudadanos identifique- 
mos los medios para ayudar a reparar el proyecto de vida de todas las personas afectadas, ya sean víctimas o victimarios. Finalmente, estamos en la obligación moral de promover la resolución pacífica del conflicto y la promulgación de valores democráticos, como la libertad y la dignidad humana en nuestras familias, colegios, universidades y lugares de trabajo, con el objetivo no solo de lograr el fin de la guerra, sino de alcanzar la anhelada paz que se refleja en justicia social y el respeto por los derechos del otro.

\section{Bibliografía}

AGREST, D. C. (2011). ¿Moral o ética? En D. C. Agrest, Inteligencia Ética para la vida cotidiana. Buenos Aires: Sudamericana.

CAPELLA, J. R. (1993). La acción en el laberinto. En J. R. Capella, Los ciudadanos Siervos (págs. 33-45). Madrid.

Centro Nacional de Memoria Histórica. (2012). Informe general: Basta ya! Bogotá: CNMH.

CORPORACIÓN HUMANAS (2009). Seminario Internacional. Judicialización de casos y reparación a mujeres víctimas de delitos de violencia sexual en el marco del conflicto armado. Bogotá: Ediciones Ántropos.

GRUPO DE MEMORIA HISTÓRICA. (2009). La masacre de El Salado: Esa guerra no era nuestra. Bogotá: Grupo de Memoria Histórica y el Comité Nacional de Reparación y Reconciliación.

MONTAÑO, J. (Agosto de 2015). Mujeres sobrevivientes de El Salado hicieron primer retorno simbólico. El Tiempo, págs. http:/www.eltiempo.com/colombia/otrasciudades/mujeres-victimas-de-el-salado-no-es-hora-de-callar/16276980.

PIEPER, A. (1991). Formas básicas de la argumentación moral y ética. En A. Pieper, Ética y Moral: una introducción a la filosofía práctica (págs. 143-152). Barcelona: Crítico.

ROLDÁN, M. E. (18 de Febrero de 2015). "Cuando los paramilitares me arrancaron la inocencia"Relato de una mujer que denunció la violación de la que fue víctima durante masacre de El Salado. El Tiempo, págs. http://www.eltiempo.com/politica/justicia/ masacre-de-el-salado-historia-mujer-violada/14881155.

RUIZ, M. (2008). Fiesta de Sangre. Revista Semana.

SEMANA. (2012). Vilencia sexual en el conflicto armado, delito con $98 \%$ de im- 
punidad. Revista Semana, http://www.semana.com/politica/articulo/violencia-sexualconflicto-armado-delito-98-impunidad/254558-3.

YOUNG, I. (2011). El modelo de la conexión social. En I. Young, Responsabilidad por la justicia (págs. 107-131). 